\title{
Efficacy of HIV antiviral polyanionic carbosilane dendrimer G2-SI6 in the presence of semen
}

\author{
This article was published in the following Dove Press journal: \\ International Journal of Nanomedicine \\ 30 May 2016 \\ Number of times this article has been viewed
}

\section{Rafael Ceña-Diez ${ }^{1-4, *}$ \\ Pilar García-Broncanol-5,* \\ Francisco Javier de la Mata ${ }^{4,6}$ \\ Rafael Gómez ${ }^{4,6}$ \\ $M^{a}$ Ángeles Muñoz- \\ Fernández ${ }^{1-4}$ \\ 'Hospital General Universitario Gregorio Marañon, ${ }^{2}$ Instituto de Investigación Sanitaria Gregorio Marañon, ${ }^{3}$ Spanish HIV HGM Biobank, ${ }^{4}$ Networking Research Center on Bioengineering, Biomaterials and Nanomedicine (CIBER-BBN), ${ }^{5}$ Laboratory of Viral Infection and Immunity, National Center of Microbiology, Health Institute of Carlos III, Majadahonda, ${ }^{6}$ Department of Organic Chemistry and Inorganic Chemistry, University of Alcalá, Alcalá de Henares, Madrid, Spain}

*These authors contributed equally to this work
Correspondence: $\mathrm{M}^{\mathrm{a}}$ Ángeles Muñoz-Fernández

Hospital General Universitario Gregorio Marañon, C/Dr Esquerdo 46, 28007

Madrid, Spain

Tel +34915868565

Email mmunoz.hgugm@gmail.com; mmunoz.hgugm@salud.madrid.org

\begin{abstract}
The development of a safe and effective microbicide to prevent the sexual transmission of human immunodeficiency virus (HIV)-1 is urgently needed. Unfortunately, the majority of microbicides, such as poly(L-lysine)-dendrimers, anionic polymers, or antiretrovirals, have proved inactive or even increased the risk of HIV infection in clinical trials, most probably due to the fact that these compounds failed to prevent semen-exposed HIV infection. We showed that G2-S16 dendrimer exerts anti-HIV-1 activity at an early stage of viral replication, blocking the gp120/CD4/CCR5 interaction and providing a barrier to infection for long periods, confirming its multifactorial and nonspecific ability. Previously, we demonstrated that topical administration of G2-S16 prevents HIV transmission in humanized BLT mice without irritation or vaginal lesions. Here, we demonstrated that G2-S16 is active against mock- and semen-exposed HIV-1 and could be a promising microbicide against HIV infection.
\end{abstract}

Keywords: G2-S16, dendrimer, HIV-1, SEVI, microbicide, antiretrovirals

\section{Introduction}

With no effective human immunodeficiency virus (HIV) vaccine available, considerable efforts have been made in the development of novel prevention strategies focused on the use of long-lasting and self-applied microbicides to halt the spread of HIV-1 during sexual intercourse. ${ }^{1}$ After numerous unsuccessful clinical trials on topical microbicides, ${ }^{2-5}$ the ineffectiveness of these topical microbicides turned out to be caused by the lack of adherence, by the induction of inflammation, and cytotoxic effect. Zirafi et $\mathrm{al}^{6}$ have shown that semen reduces the sensitivity of HIV to poly(L-lysine) (PLL)-dendrimer SPL7013 having 32 anionic naphthalene sulfonate groups in the periphery (VivaGel ${ }^{\circledR}$; Starpharma, Melbourne, VIC, Australia $)^{7,8}$ and to other anionic polymers acting on target HIV, and to the nucleotide or non-nucleoside reverse transcriptase inhibitors or the integrase inhibitors acting on intracellular targets. ${ }^{2,5,9-14}$ These dendrimers with highly potent inhibitory effect on HIV in vitro were considered for microbicide development, but failed to prevent HIV transmission in people. ${ }^{6}$ All dendrimers were 18 - to 21 -fold less active against semen-treated virus and failed to prevent semen-exposed HIV infection. ${ }^{6}$ They have also shown that maraviroc, currently under consideration for microbicide development, acts equally against mock- and semen-exposed HIV. ${ }^{6}$

The negative influence of semen on the efficacy of various classes of nanocompounds against HIV infection may explain why many microbicides that show high efficacy in vitro failed in clinical trials. We studied whether this effect can be observed in our G2-S16 anionic carbosilane dendrimer, which has been in a preclinical phase as an anti-HIV microbicide. 


\section{Materials and methods}

\section{Study design}

Semen samples derived from more than ten deidentified healthy donors were collected after obtaining written informed consent from them at the Spanish HIV HGU BioBank in Madrid, Spain. ${ }^{15}$ All ejaculates were allowed to liquefy from 30 minutes to 2 hours, and the semen samples were pooled and stored in $500 \mu \mathrm{L}$ aliquots at $-20^{\circ} \mathrm{C}$. Experiments were performed with rapidly defrosted aliquots and the remaining samples were ruled out. The study was approved by the Ethics Committee of Clinical Research, Hospital General Universitario Gregorio Gregorio Marañon. TZM.bl cell line and primary peripheral blood mononuclear cells (PBMC) were pretreated with serial dilutions of G2-S16 polyanionic carbosilane dendrimer infected with HIV-1 isolates that were treated with buffer or semen. Infection values were evaluated by measuring luciferase in luminescence-based assay 72 hours after infection. All experiments were carried out in triplicate and analyzed statistically.

\section{Reagents}

G2-S16 consists of second-generation carbosilane dendrimer scaffold built from a silicon atom core, which is fully capped on the surface with 16 sulfonate groups. G2-S16 $\left(\mathrm{C}_{112} \mathrm{H}_{244} \mathrm{~N}_{8} \mathrm{Na}_{16} \mathrm{O}_{48} \mathrm{~S}_{16} \mathrm{Si}_{13}\right.$, molecular weight: $\left.3717.15 \mathrm{~g} / \mathrm{mol}\right)$ was synthesized according to the previously published method (Figure 1). ${ }^{16}$ Generation is described as the number of repeating layers of silicon atoms forming the dendrimer. G2-S16 dendrimer was dissolved in distilled water and reagents in phosphate-buffered saline to a final concentration of $1 \mathrm{mM}$. Dilutions in micromolar range were formed in distilled water from the stock.

\section{Cell culture and virus strains}

TZM.bl cell line (NIH AIDS Research and Reference Reagent Program) was cultured as described. ${ }^{17}$ Blood samples were obtained from buffy coats of healthy anonymous donors from the transfusion center of Madrid following national guidelines. PBMC were isolated on a Ficoll-hypaque

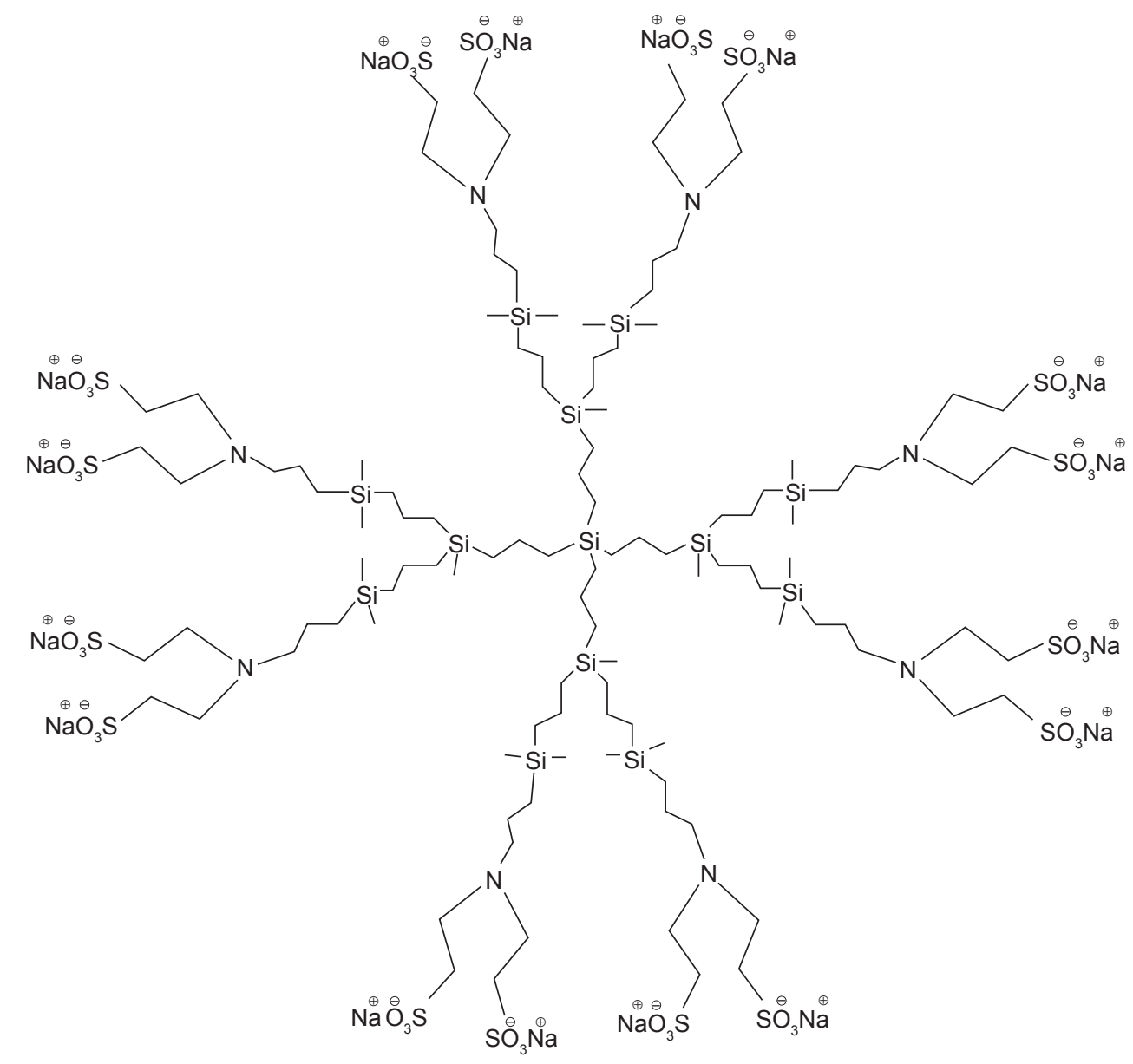

Figure I Structure of polyanionic carbosilane dendrimer G2-S16.

Notes: Representative scheme of the second-generation carbosilane dendrimer G2-S16. Schematic structure of carbosilane dendrimer bearing sulfonate groups at his periphery and synthesized by Michael addition. 
density gradient (Rafer S.L., Zaragoza, Spain) following the current procedures of Spanish HIV HGM BioBank. ${ }^{15}$ Prior to treatment with G2-S16, PBMC were stimulated with the mitogen phytohemagglutinin for 48 hours $(2 \mu \mathrm{g} / \mathrm{mL}$; Thermo Fisher Scientific, Waltham, MA, USA). Viral stocks of CCR5-tropic R5-HIV-1 ${ }_{\mathrm{NL}(\mathrm{AD} 8)}$ laboratory strain and transmitter/founder (T/F) (pCH058.c and pTHRO.c) R5-HIV-1 strains were obtained by transient transfection of pNL(AD8), pCH058.c/2960, and pTHRO.c/2626 plasmids, respectively (NIH AIDS Research and Reference Reagent Program) in 293T cells (American Type Culture Collection [ATCC], Manassas, VA, USA). Viral stocks were previously clarified by centrifugation to evaluate the viral titer by using HIV-1 p24 gag enzyme-linked immunosorbent assay kit (INNOTEST ${ }^{\circledR}$; Innogenetics, Ghent, Belgium).

\section{Inhibition of HIV infection in the presence or absence of semen through the action of G2-S16 dendrimer in TZM.bl cells and in primary PBMC}

To evaluate the activity of G2-S16 in the presence of semen, TZM.bl and PBMC were seeded into 96-well plates at a density of $15 \times 10^{3}$ cells $/ 200 \mu \mathrm{L}$ and $200 \times 10^{3}$ cells $/ 200 \mu \mathrm{L}$, respectively. After 24 hours, TZM.bl and activated PBMC were treated with various concentrations of tested G2-S16 for 1 hour at $37^{\circ} \mathrm{C}$ in the presence of $5 \% \mathrm{CO}_{2}$ prior to the infection. R5-HIV-1 ${ }_{\mathrm{NL}(\mathrm{AD} 8)}$ or R5-tropic T/F HIV-1 strains were incubated with semen for 5 minutes to obtain semen concentrations of $10 \%$ during virion treatment. After the semen/virus incubation, the cells were infected with $14 \mu \mathrm{L}$ of semen-virus (20 ng virus/ $1 \times 10^{6}$ cells) or PBS-virus (20 ng virus $/ 1 \times 10^{6}$ cells). The final well concentrations of semen were $0.67 \%$ and $0 \%$, respectively. TZM.bl and PBMC were incubated for 2 and 3 hours, respectively, in culture conditions and then washed twice and replaced by $200 \mu \mathrm{L}$ fresh medium. Three days later, PBMC supernatants were collected and $100 \mu \mathrm{L}$ was added to TZM.bl cells, which had been seeded in 96 -well plates at a density of $15 \times 10^{3}$ cells $/ 100 \mu \mathrm{L}$ per well the day before. Two days later, HIV-1 replication was determined in TZM.bl cells and PBMC after quantification of luciferase expression (Promega Corporation, Fitchburg, WI, USA). Fifty percent of the effective concentrations $\left(\mathrm{IC}_{50}\right)$ were calculated by using CalcuSyn software (Biosoft, Cambridge, UK), based on the median effect principle. ${ }^{18}$

\section{$\mathrm{IC}_{50}$ calculation and statistical analysis}

For $\mathrm{G} 2-\mathrm{S} 16$ polyanionic carbosilane dendrimer, $\mathrm{IC}_{50}$ was calculated using CalcuSyn software. All statistical analyses were performed using GraphPad Prism v.6 (GraphPad Software, Inc., La Jolla, CA, USA). Statistical analysis including the calculation of the mean, standard deviation, standard error of the mean, and $P$-values was performed using MannWhitney $U$ nonparametric test. The significance level was set at $P<0.05$.

\section{Results}

To assess if semen increases the infectious capacity of HIV-1 by affecting the inhibitory potential of the G2-S16 polyanionic carbosilane dendrimer, we performed an inhibition assay on TZM.bl cells with three R5-HIV-1 strains in the presence of semen. It was observed that HIV-1 infection was enhanced by the presence of semen by $1 \log$ when compared to mock-exposed HIV-1 infection in the absence of treatment (Figure 2). Out of the R5-HIV-1 ${ }_{\mathrm{NL}(\mathrm{AD} 8)}$ and T/F R5 pCH058.c and pTHRO.c strains studied in the absence of semen, G2-S16 was slightly more effective against R5-HIV-1 ${ }_{\mathrm{NL}(\mathrm{AD} 8)}$, showing inhibitory values over $95 \%$ from $1 \mu \mathrm{M}$ onward $\left(\mathrm{IC}_{50}=0.04 \mu \mathrm{M}\right)$. Interestingly, pTHRO.c and pCH058.c T/F R5-HIV-1 were also inhibited at nontoxic concentrations of G2-S16 (1 and $5 \mu \mathrm{M}$ onward, respectively). The highest $\mathrm{IC}_{50}$ of $0.886 \mu \mathrm{M}$ was obtained against pCH058.c T/F R5-HIV-1 (Figure 3; Table 1).

When the infectivity of HIV-1 was enhanced by the presence of semen, we observed an increase in $\mathrm{IC}_{50}$. However, G2-S16 maintained high values of protection against HIV-1 infection at higher nontoxic concentrations $(15-20 \mu \mathrm{M})$ (Figure 3), in comparison with the concentrations obtained in the absence of semen $(1-5 \mu \mathrm{M})$. In the presence of semen, G2-S16 showed no inhibitory activity against any of the three R5-HIV-1 strains at concentrations $<1 \mu \mathrm{M}$. However, G2-S16 completely halted HIV-1 infection in all cases when it was used at concentrations over $15 \mu \mathrm{M}$. G2-S16 showed $\mathrm{IC}_{50}$ values of $8.17,1.87$, and $11.08 \mu \mathrm{M}$ against R5-HIV- $1_{\mathrm{NL}(\mathrm{AD} 8)}$ ' pCH058.c, and pTHRO.c R5-HIV-1, respectively, in the presence of semen (Table 1).

Interestingly, G2-S16 had an $\mathrm{IC}_{50}$ lower than $0.01 \mu \mathrm{M}$ against pTHRO.c and R5-HIV-1 ${ }_{\mathrm{NL}(\mathrm{AD} 8)}$ strains in the absence of semen. G2-S16 was found to be 204-fold, 125-fold, and twofold less effective against semen-exposed R5-HIV- $1_{\mathrm{NL}(\mathrm{AD} 8)}$ pCH058.c, and pTHRO.c virus, respectively (Table 1). However, inhibition values of $100 \%$ were obtained in the nontoxic concentration range of G2-S16 (Figure 3).

To confirm these results in a more physiological model, we studied the inhibitory ability of G2-S16 in PBMC against a single R5-HIV-1 strain. We found that the inhibitory values of R5-HIV-1 $1_{\mathrm{NL}(\mathrm{AD} 8)}$ in PBMC were slightly lower than those 

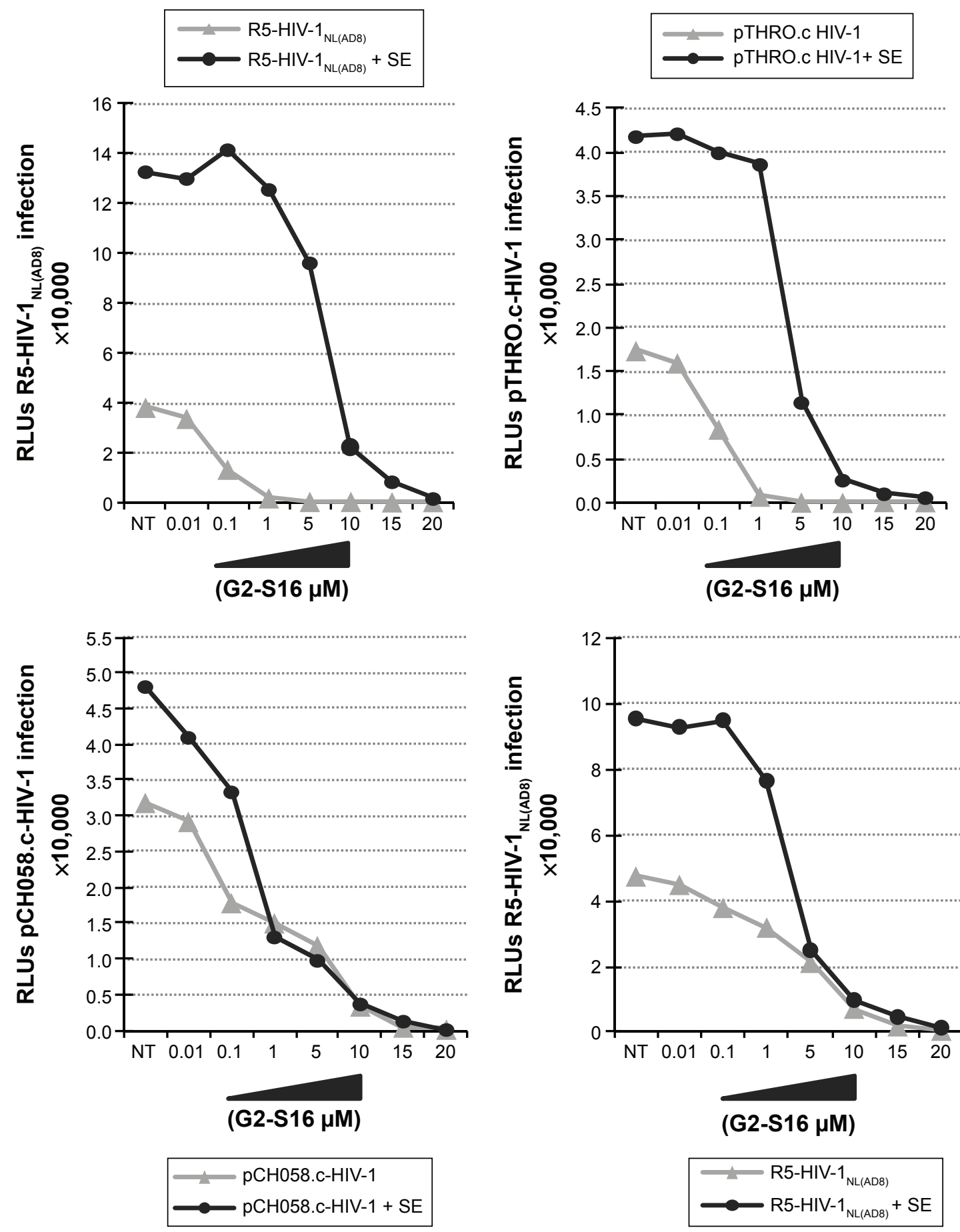

Figure 2 Effect of SEVI on the antiviral activity of G2-SI6 polyanionic carbosilane dendrimer to block HIV-I infection of TZM.bl cells and PBMC.

Notes: Cells were pretreated with G2-SI6 at a concentration range of 0.0I-20 $\mu$ M. After I hour, the cells were infected with R5-HIV-I ${ }_{\text {NL(AD8) }}$ PCH058.c, and pTHRO.c in the absence and presence of SE at a concentration of $20 \mathrm{ng} / 10^{6}$ cells. RLU values were measured 72 hours after infection by quantification of luciferase expression. Data represent the mean $\pm \operatorname{SEM}(n=3)$.

Abbreviations: HIV, human immunodeficiency virus; PBMC, peripheral blood mononuclear cells; SE, semen; SEM, standard error of mean; SEVI, semen-derived enhancer of viral infection; RLU, relative light unit.

obtained in TZM.bl cells, although the tendency shown by the results was similar. Interestingly, G2-S16 inhibited 90\% of R5-HIV- $1_{\mathrm{NL}(\mathrm{AD} 8)}$ at $10 \mu \mathrm{M}$ in the absence of semen and $98 \%$ at $20 \mu \mathrm{M}$ in the presence of semen (Figure 3). The inhibition values of HIV-1 infection were practically not affected by the presence of semen when the cells were pretreated with G2-S16, resulting in minimal changes in $\mathrm{IC}_{50}$ values in the absence $\left(\mathrm{IC}_{50}=3.345 \mu \mathrm{M}\right)$ or presence $\left(\mathrm{IC}_{50}=4.938\right)$ of semen. In other words, the difference was only 1.47 -fold higher in the presence of semen in comparison to that in its absence (Table 1). 

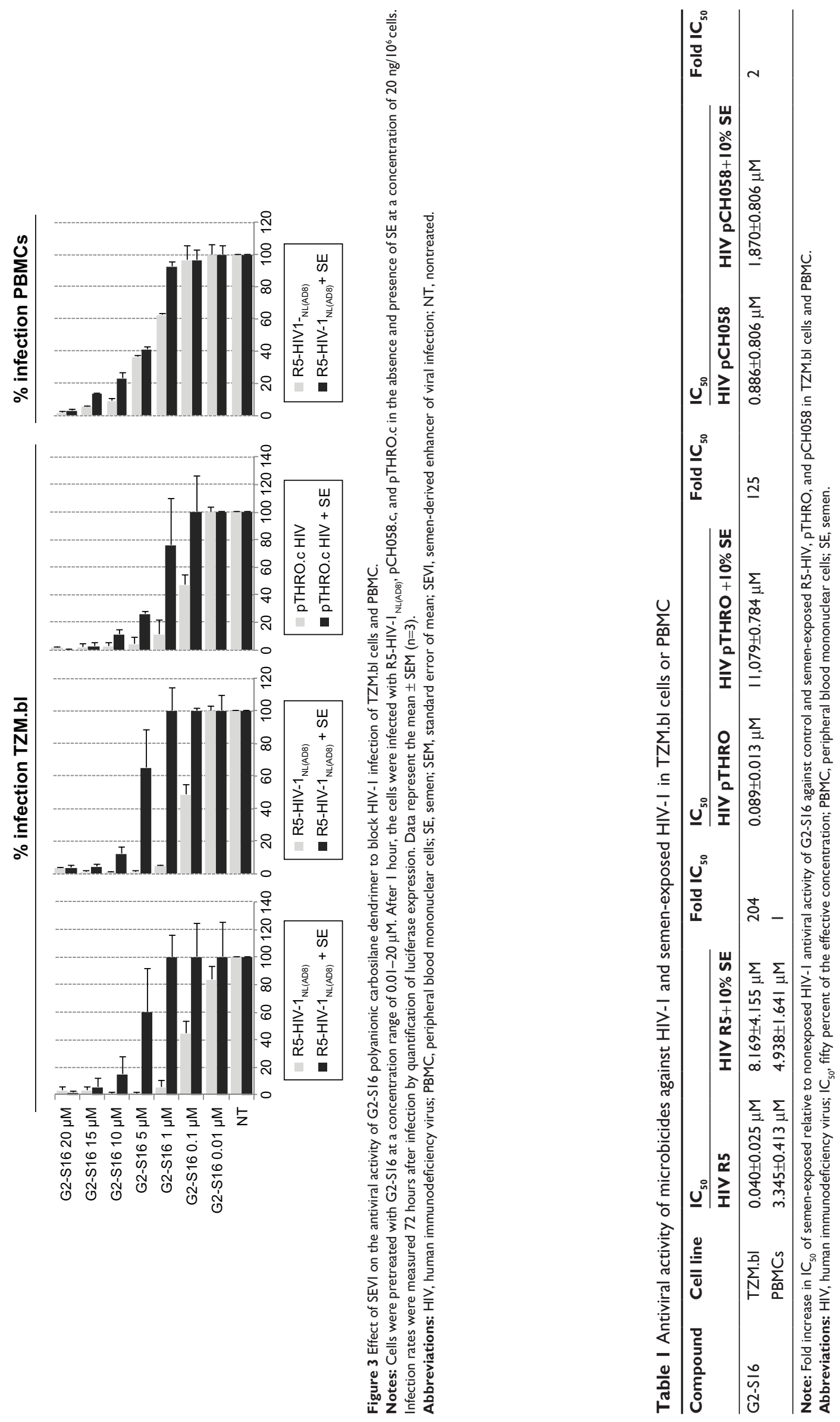
To sum up, G2-S16 was active against mock- and semen-exposed HIV-1. G2-S16 prevented semen-treated HIV-1 infection of TZM.bl cells and PBMC at nontoxic concentrations.

\section{Discussion}

Polyanionic carbosilane dendrimers have shown promising outcomes in inhibiting HIV infection. ${ }^{17,19,20}$ Some time ago, the main limitations of the first topical "nanomicrobicide" PLL-dendrimer SPL 7013 were the lack of broad anti-HIV-1 activity against R5-HIV-1 strains ${ }^{21}$ and the increased risk for HIV-1 acquisition associated with epithelial injury after 7-14 days of twice-daily administration. ${ }^{22}$ Seminal amyloid is critical for decreasing the antiviral efficacy of SPL7013 PLL-dendrimer and anionic polymers because semen lacking HIV-enhancing activity does not impair the drug efficacy, whereas synthetic semen-derived enhancer of viral infection amyloid fibrils decrease the drug efficacy as the semen itself. ${ }^{6}$ Seminal amyloids can bind to HIV virions and efficiently enhance and accelerate their attachment to target cells. ${ }^{6,23-26}$ They shorten the time of exposure of virions to microbicides acting outside the cell and can impede the accessibility of SPL7013 PLL-dendrimer and anionic polymers to the viral membrane and glycoproteins. In contrast to SPL7013 anionic dendrimer that targets HIV components, maraviroc inhibits HIV entry by binding to the cellular CCR5 coreceptor. ${ }^{27}$ Therefore, if maraviroc occupies all CCR5 receptors at the cell membrane, it can prevent viral entry independent of the presence of amyloid fibrils or semen. To sum up, compounds targeting cellular factors could be promising microbicides.

We studied G2-S16 polyanionic carbosilane dendrimer because it is considered safe to be used as a topical vaginal microbicide, as shown by not only in vitro but also in vivo results. ${ }^{17,19,20} \mathrm{G} 2-\mathrm{S} 16$ presents high biosafety and low toxicity in PBMC, shows high anti-HIV activity in urogenital epithelial cells against HIV-1-R5-, X4-, and dual-tropic viruses, their various subtypes, and T/F HIV-1 strains. G2-S16 is stable over a broad $\mathrm{pH}$ range ( $\mathrm{pH}$ in vagina: $4-5.8$ and $\mathrm{pH}$ in seminal fluid: 8-8.5), maintaining the anti-HIV-1 activity. G2-S16 decreases HIV-1 infection when the cells are pretreated for a short duration. Its inhibitory effect is prolonged over time, protects monolayer for tight junction disruption induced by HIV-1, and impedes partial transmission of HIV-1 through epithelial monolayer and blocks subsequent HIV-1 infection of PBMC. G2-S16 does not induce cell proliferation or modify the expression of CD4, CD8, CCR5, and CXCR4 and does not alter markers of activation in the subsets of PBMC. G2-S16 does not alter vaginal microbiota, retains its antiviral activity for up to 2-3 hours after HIV-1 inoculation, blocks an early step in the HIV-1 infection cycle, acts nonspecifically toward Env- and CD4-expressing cells in a dose-dependent manner (although predominantly it acts toward the host CD4 cells), and is involved in HIV-1 attachment and HIV-1 entry steps on activated-PBMC. G2-S16 treatment of HIV-1 decreases the infectivity of the viral particles in a dose-dependent and tropism-independent manner, indicating that this dendrimer acts strongly on the virion, inactivating it. G2-S16 does neither alter semen motility nor affect other functions of the semen. ${ }^{16,19,28}$ No irritation or vaginal lesions were detected in rabbits after 2 weeks of intravaginal G2-S16 application ${ }^{19}$ or in CD1(ICR) mice after G2-S16 vaginal administration. ${ }^{19}$ The application of one dose of $1.5 \%, 3 \%$, and $4.5 \%$ of G2-S16 to hydroxyethylcellulose (HEC) gel-treated BALB/c at various consecutive time periods does not cause disruption of the epithelial cells or produce damage in the vaginal mucosa. Topical vaginal G2-S16 microbicide administration inhibits HIV-1 infection by $85 \%$ in humanized bone marrow-liverthymus mice without symptoms, including inflammation and vaginal irritation. ${ }^{29}$

Consistent with these results and in accordance with the fact that semen is the major vector fueling the global spread of HIV infection, we carried out experiments on the inhibition of G2-S16 at maximum nontoxic concentrations $(15-20 \mu \mathrm{M})$ in the presence of amyloid fibrils of semen against R5-HIV-1 ${ }_{\mathrm{NL}(\mathrm{AD} 8)}, \mathrm{T} / \mathrm{F}$ CH058, and THRO R5-HIV-1 strains (Figures 2 and 3). Although it is true that an increase in $\mathrm{IC}_{50}$ was found for G2-S16 against HIV-1 for which the infectivity has been enhanced by the presence of semen, it was clearly found that G2-S16 maintains its inhibitory effect on HIV-1 infection at nontoxic concentrations.

The differences in results obtained between SPL7013 and G2-S16 dendrimers could be because SPL7013 is a PLLdendrimer with 32 anionic naphthalene sulfonate groups in the periphery, and it has been shown that semen components or the alkaline $\mathrm{pH}$ of semen decreases the anti-HIV activity of polyanions by neutralizing their negative charge $e^{24,30-33}$ or by competitive binding to the viral envelope. ${ }^{34}$ These data provide conceivable explanations as to why semen abrogates the antiviral activity of polyanions. G2-S16, a polyanionic carbosilane dendrimer with 16 sulfonate groups in the periphery, not only decreases the anti-HIV-1 activity of polyanions by neutralizing their negative charge or by competitive binding (target viral G2-S16/gp120 complex) but also binds CD4 receptor in areas important for CD4/gp120 and CXCR4 or CCR5/gp120 complexes (target cell factors). G2-S16 prevents 
HIV entry in a manner that is independent of the number of viral particles or the presence of semen, and G2-S16 also acts as an inhibitor of cell-to-cell transmission. ${ }^{19,20}$ To summarize, G2-S16 possesses a multifactorial and nonspecific ability because it acts as a virucidal agent, an inhibitor of entry of the virus, a barrier to infection for long periods of time, and an inhibitor of cell-to-cell HIV-1 transmission.

We suggest that the efficacy of microbicidal candidates for the prevention of sexual HIV transmission should also be determined in the presence of semen and $\mathrm{T} / \mathrm{F}$ viruses in vitro, in order to resemble as closely as possible the physiological environment of HIV transmission and to avoid possible negative results of future treatments against HIV in clinical trials. We should not forget that the HIV is able to use the heterogeneity of its heavily glycosylated envelope gp 120 to bind the most important $\mathrm{C}$-type lectin receptors on the surface of epithelial dendritic cells. Also, C-type lectin receptors of epithelial dendritic cells should be researched as targets for vaginal (and perhaps anorectal) microbicides. Consistent with this hypothesis, combinations of G2-S16 dendrimer and compounds/antiretrovirals disrupting the infection-increasing activity of semen should be assessed in future studies.

\section{Conclusion}

G2-S16 carbosilane dendrimer is considered safe to be used as a topical vaginal microbicide, as shown by not only in vitro but also in vivo results. We clearly demonstrated that G2-S16 dendrimer maintains its inhibitory effect at nontoxic concentrations against HIV for which the infectivity has been enhanced by the presence of amyloid fibrils of semen. This opens up the gate for future experiments, such as in vivo assays, in the presence of semen and provides encouraging prospects of achieving a topical microbicide that is able to overcome the clinical trials satisfactorily.

\section{Acknowledgments}

This work has been partially funded by the RD12/0017/0037 project as part of the Acción Estratégica en Salud, Plan Nacional de Investigación Científica, Desarrollo e Innovación Tecnológica 2008-2011 and cofinanced by Instituto de Salud Carlos III (Subdirección General de Evaluación) and Fondo Europeo de Desarrollo Regional, RETIC PT13/0010/0028, Fondo de Investigacion Sanitaria (grant number PI13/02016), CTQ2011-23245 (MIMECO), Comunidad de Madrid (grant numbers S-2010/BMD-2351 and S-2010/BMD-2332), CYTED 214RT0482. CIBER-BBN is an initiative funded by the VI National R\&D\&i Plan 2008-2011, IniciativaIngenio 2010, the Consolider Program, and CIBER Actions and financed by the Instituto de Salud Carlos III with assistance from the European Regional Development Fund.

\section{Disclosure}

The authors report no conflicts of interest in this work.

\section{References}

1. Cottrell ML, Kashuba AD. Topical microbicides and HIV prevention in the female genital tract. J Clin Pharmacol. 2014;54(6):603-615.

2. Grant RM, Hamer D, Hope T, et al. Whither or wither microbicides? Science. 2008;321(5888):532-534.

3. Vanpouille C, Arakelyan A, Margolis L. Microbicides: still a long road to success. Trends Microbiol. 2012;20(8):369-375.

4. Fichorova RN, TuckerLD, AndersonDJ. The molecularbasis of nonoxynol9-induced vaginal inflammation and its possible relevance to human immunodeficiency virus type 1 transmission. J Infect Dis. 2001;184(4): 418-428.

5. McCormack S, Ramjee G, Kamali A, et al. PRO2000 vaginal gel for prevention of HIV-1 infection (Microbicides Development Programme 301): a phase 3, randomised, double-blind, parallel-group trial. Lancet. 2010;376(9749):1329-1337.

6. Zirafi O, Kim KA, Roan NR, et al. Semen enhances HIV infectivity and impairs the antiviral efficacy of microbicides. Sci Transl Med. 2014; 6(262):262ra157.

7. Bernstein DI, Stanberry LR, Sacks S, et al. Evaluations of unformulated and formulated dendrimer-based microbicide candidates in mouse and guinea pig models of genital herpes. Antimicrob Agents Chemother. 2003;47(12):3784-3788.

8. Price CF, Tyssen D, Sonza S, et al. SPL 7013 Gel (VivaGel(R)) retains potent HIV-1 and HSV-2 inhibitory activity following vaginal administration in humans. PLoS One. 2011;6(9):e24095.

9. Abdool Karim SS, Richardson BA, Ramjee G, et al. Safety and effectiveness of BufferGel and 0.5\% PRO2000 gel for the prevention of HIV infection in women. AIDS. 2011;25(7):957-966.

10. Huskens D, Vermeire K, Profy AT, Schols D. The candidate sulfonated microbicide, PRO 2000, has potential multiple mechanisms of action against HIV-1. Antiviral Res. 2009;84(1):38-47.

11. Mohan P, Schols D, Baba M, De Clercq E. Sulfonic acid polymers as a new class of human immunodeficiency virus inhibitors. Antiviral Res. 1992;18(2):139-150.

12. Rusconi S, Moonis M, Merrill DP, et al. Naphthalene sulfonate polymers with CD4-blocking and anti-human immunodeficiency virus type 1 activities. Antimicrob Agents Chemother. 1996;40(1): 234-236.

13. Scordi-Bello IA, Mosoian A, He C, et al. Candidate sulfonated and sulfated topical microbicides: comparison of anti-human immunodeficiency virus activities and mechanisms of action. Antimicrob Agents Chemother. 2005;49(9):3607-3615.

14. Van Damme L, Govinden R, Mirembe FM, et al. Lack of effectiveness of cellulose sulfate gel for the prevention of vaginal HIV transmission. N Engl J Med. 2008;359(5):463-472.

15. García-Merino I, de Las Cuevas N, Jiménez JL, et al. The Spanish HIV BioBank: a model of cooperative HIV research. Retrovirology. 2009;6:27.

16. Rasines B, Sánchez-Nieves J, Maiolo M, et al. Synthesis, structure and molecular modelling of anionic carbosilane dendrimers. Dalton Trans. 2012;41(41):12733-12748.

17. Vacas Córdoba E, Arnaiz E, Relloso M, et al. Development of sulphated and naphthylsulphonated carbosilane dendrimers as topical microbicides to prevent HIV-1 sexual transmission. AIDS. 2013;27(8): 1219-1229.

18. Chou TC, Talalay P. Quantitative analysis of dose-effect relationships: the combined effects of multiple drugs or enzyme inhibitors. $A d v$ Enzyme Regul. 1984;22:27-55. 
19. Chonco L, Pion M, Vacas E, et al. Carbosilane dendrimer nanotechnology outlines of the broad HIV blocker profile. J Control Release. 2012;161(3):949-958.

20. Sánchez-Rodríguez J, Vacas-Córdoba E, Gómez R, De La Mata FJ, Muñoz-Fernández MA. Nanotech-derived topical microbicides for HIV prevention: the road to clinical development. Antiviral Res. 2015; 113:33-48.

21. Telwatte S, Moore K, Johnson A, et al. Virucidal activity of the dendrimer microbicide SPL7013 against HIV-1. Antiviral Res. 2011;90(3): 195-199.

22. Moscicki AB, Kaul R, Ma Y, et al. Measurement of mucosal biomarkers in a phase 1 trial of intravaginal 3\% StarPharma LTD 7013 gel (VivaGel) to assess expanded safety. J Acquir Immune Defic Syndr. 2012;59(2):134-140.

23. Arnold F, Schnell J, Zirafi O, et al. Naturally occurring fragments from two distinct regions of the prostatic acid phosphatase form amyloidogenic enhancers of HIV infection. J Virol. 2012;86(2):1244-1249.

24. Neurath AR, Strick N, Li YY. Role of seminal plasma in the anti-HIV-1 activity of candidate microbicides. BMC Infect Dis. 2006;6:150.

25. Roan NR, Muller JA, Liu H, et al. Peptides released by physiological cleavage of semen coagulum proteins form amyloids that enhance HIV infection. Cell Host Microbe. 2011;10(6):541-550.

26. Usmani SM, Zirafi O, Müller JA, et al. Direct visualization of HIVenhancing endogenous amyloid fibrils in human semen. Nat Commun. 2014;5:3508.

27. Tan Q, Zhu Y, Li J, et al. Structure of the CCR5 chemokine receptorHIV entry inhibitor maraviroc complex. Science. 2013;341(6152): 1387-1390.
28. Sepúlveda-Crespo D, Gómez R, De La Mata FJ, Jimenez JL, MunozFernandez MA. Polyanionic carbosilane dendrimer-conjugated antiviral drugs as efficient microbicides: Recent trends and developments in HIV treatment/therapy. Nanomedicine. 2015;11(6):1481-1498.

29. Sepúlveda-Crespo D, Serramía MJ, Tager AM, et al. Prevention vaginally of HIV-1 transmission in humanized BLT mice and mode of antiviral action of polyanionic carbosilane dendrimer G2-S16. Nanomedicine. 2015;11(6):1299-1308.

30. Lackman-Smith C, Osterling C, Luckenbaugh K, et al. Development of a comprehensive human immunodeficiency virus type 1 screening algorithm for discovery and preclinical testing of topical microbicides. Antimicrob Agents Chemother. 2008;52(5):1768-1781.

31. Tan S, Lu L, Li L, et al. Polyanionic candidate microbicides accelerate the formation of semen-derived amyloid fibrils to enhance HIV-1 infection. PLoS One. 2013;8(3):e59777.

32. Keller MJ, Mesquita PM, Torres NM, et al. Postcoital bioavailability and antiviral activity of $0.5 \%$ PRO 2000 gel: implications for future microbicide clinical trials. PLoS One. 2010;5(1):e8781.

33. Herold BC, Mesquita PM, Madan RP, Keller MJ. Female genital tract secretions and semen impact the development of microbicides for the prevention of HIV and other sexually transmitted infections. Am J Reprod Immunol. 2011;65(3):325-333.

34. Patel S, Hazrati E, Cheshenko N, et al. Seminal plasma reduces the effectiveness of topical polyanionic microbicides. J Infect Dis. 2007; 196(9):1394-1402.
International Journal of Nanomedicine

\section{Publish your work in this journal}

The International Journal of Nanomedicine is an international, peerreviewed journal focusing on the application of nanotechnology in diagnostics, therapeutics, and drug delivery systems throughout the biomedical field. This journal is indexed on PubMed Central, MedLine, CAS, SciSearch ${ }^{\circledR}$, Current Contents ${ }^{\circledR} /$ Clinical Medicine,

\section{Dovepress}

Journal Citation Reports/Science Edition, EMBase, Scopus and the Elsevier Bibliographic databases. The manuscript management system is completely online and includes a very quick and fair peer-review system, which is all easy to use. Visit http://www.dovepress.com/ testimonials.php to read real quotes from published authors. 